
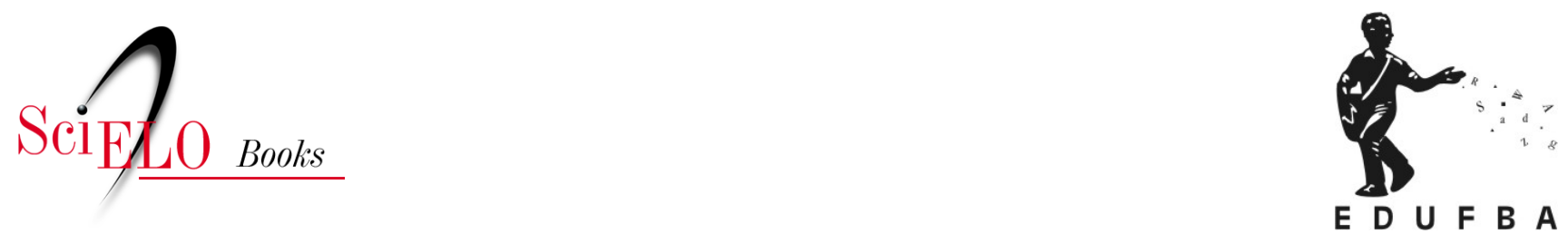

\title{
A santificação e a visualidade
}

\author{
Eduardo Tudella
}

\section{SciELO Books / SciELO Livros / SciELO Libros}

TUDELLA, E. A santificação e a visualidade. In: A luz na gênese do espetáculo [online]. Salvador: EDUFBA, 2017, pp. 235-264. ISBN: 978-85-232-1858-4.

https://doi.org/10.7476/9788523218584.0009.

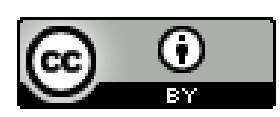

All the contents of this work, except where otherwise noted, is licensed under a Creative Commons Attribution $\underline{4.0 \text { International license. }}$

Todo o conteúdo deste trabalho, exceto quando houver ressalva, é publicado sob a licença Creative Commons Atribição 4.0.

Todo el contenido de esta obra, excepto donde se indique lo contrario, está bajo licencia de la licencia Creative Commons Reconocimento 4.0. 


\section{A SANTIFICAÇÃO E A VISUALIDADE}

O universo criado pela literatura, pela música e pelas artes visuais repercutiu na práxis cênica, produzindo trocas entre as mais diversas expressões artísticas e abrindo intercâmbios de "mão dupla" que resultaram em uma profunda interação estética. Tal universo apresenta variáveis que interagem com a conjuntura político-religiosa, preponderante na economia e na construção da história moderna. O presente capítulo trata de proposições do Barroco para observar seu impacto visual na modernidade.

\section{FRONTEIRAS MANEIRISTAS}

A ópera, como exemplo, provocou contexto visual particular ao espetáculo, produzindo ecos e extensões que se instalaram progressivamente, desde as primeiras décadas do século XVI. Certas reações radicais de artistas do período estenderam-se até a segunda década do século XVI, caracterizando-se como um 
momento na história da arte, principalmente das artes visuais, conhecido progressivamente como Maneirismo e definido assim por Hugh Honour e John Fleming (1984, p. 379, tradução nossa).: "[...] [O maneirismo] foi construído como uma reação ou extensão dos ideais da Alta Renascença, como uma expressão da crise espiritual desse momento, [...]".

Também se pode compreender a atitude maneirista como estilização estética rigorosa, o que abriria espaços até mesmo para que se apreenda na implantação da práxis cênica em um espaço formalmente definido e construído para esse fim, um princípio de natureza maneirista, por vezes interpretado como atitude de confinamento/aprisionamento do acontecimento espetacular. A sistematização do palco e dos bastidores, como espaços definidos e constantes - incluindo a tecnologia que permite a realização de espetáculos - redundou numa rigorosa estilização estética da cena, que buscou sucessivo "refinamento". Certos exageros tecnológicos podem ser compreendidos também como "maneirismo", numa crítica que os considera nocivos para a abordagem artística.

Os comentadores concordam que a obra de Giorgio Vasari contribuiu para a disseminação do termo Maneirismo, como caracterização da obra de artistas do período. A palavra italiana maniera aparece inúmeras vezes nos seus escritos, sendo traduzida como maneira, modo, jeito e até como estilo. Em qualquer desses casos, relacionando-a ao modo particular e até peculiar de cada artista. Já na introdução de sua obra, Vasari aplicou diversas vezes a palavra maniera de forma destacada. (VASARI, 1993) Referindo-se à pintura a óleo, ele aplicou o termo para sugerir excelência e modo particular de aplicação de técnicas:

Este modo de colorir revela mais as cores, além disso, exige diligência e cuidado, porque o óleo em si deixa o colorido mais suave, mais doce, mais delicado, e torna a mixagem e o esfumado mais fácil do que nos outros casos, e quanto mais continuadamente [sem permitir que a tinta seque] você trabalha, mais facilmente elas se misturam e se fundem umas às outras. E, em suma, os artistas produzem assim, graciosidade, vivacidade, galhardeza nas suas figuras, de tal modo que muitas vezes nos fazem parecer em relevo as suas figuras, e principamente quando elas são contornadas com bom desenho, com invenção e bela maneira. ${ }^{2}$ (VASARI, 1993, p. 81)

\footnotetext{
1 "It has been construed as either a reaction against or an extension of the ideals of the High Renascence, as an expression of the spiritual crises of the time [...]."

2 "Questa maniera di colorire accende più i colori, né altro bisogna che diligenza et amore, perché l'olio in sé si reca il colorito più morbido, più dolce e delicato e di unione e sfumata maniera più facile che li altri, e mentre che fresco si lavora, i colori si mescolano e si uniscono l'uno con l'altro più facilmente. Et insomma li artefici danno
} 
Segundo alguns comentadores o maneirismo está ligado, nas artes visuais, à iniciativa de um grupo de pintores que reagiam aos pressupostos renascentistas, pesquisando a visualidade da Roma antiga, incluindo a escultura e a pintura de grandes mestres do passado. A adjetivação do trato específico de um artista forja a expressão bella maniera para indicar o atendimento a determinado conjunto de procedimentos que caracterizariam o modelo de suavidade, identificado em Leonardo da Vinci ou Rafael, ambos mencionados como exemplos para indicar a qualidade esperada e difundida na Alta Renascença. A bella maniera encontraria oposição já no tratamento elaborado por artistas do século XVI, listados pelos estudiosos como maneiristas. Alguns deles afirmam que o termo maneirismo foi utilizado pela primeira vez em um texto de Luigi Lanzi [(1732-1810) historiador, pesquisador da arte clássica e italiana da Renascença], como no exemplo a seguir:

[...] massas de pleno e de vazio, de luzes e sombras, não são equilibradas de acordo com a vontade, como fazem os maneiristas, mas, na imitação da seleção natural [da natureza]: tudo é arte, mas tudo é facilidade e ocultação da arte. A Escola de Atenas, [pintada] no Vaticano, neste gênero é, talvez, o empreendimento mais notável que há no mundo [Figura 52]. ${ }^{3}$ (LANZI, 1972, p. 222, grifo nosso)

Em A Escola de Atenas (Scuola di Atene), de Rafael [Rafaello Sanzio (1493-1520)], pintada entre 1506 e 1510, podem ser encontrados cânones da mais alta expressão da visualidade do Renascimento. O empenho no atendimento à proporção e à perspectiva, na humanização das figuras, na fidelidade às narrativas usadas como ponto de partida e argumento, alcançavam extremos de representatividade, de acordo com alguns críticos. Por outro lado, cabe registrar a moldura que envolve a cena instalada na obra e anuncia um tratamento visual que só apareceria como forma permanente no teatro, um século depois - a boca de cena - com a construção do Teatro Farnese, em 1618, projeto de Giovanni Batista Aleotti.

Rafael indica uma trilha visual que passaria a interessar às artes cênicas e se consolidaria como um modelo que permanece em prática até hoje - mesmo sendo incessantemente combatido -, no qual a ação teatral é inscrita dentro da caixa

in questo modo bellissima grazia e vivacità e gagliardezza alle figure loro, talmente che spesso ci fanno parere di rilievo, e che elle eschino de la tavola, e massimamente quando elle sono continovate di buono disegno, con invenzione e bella maniera." (A tradução para a língua portuguesa é de Ana Maria Santanchè)

3 “[...] masse de' pieni e de' vuoti, de' lumi e delle ombre sono equilibrate non a norma del volere, come ne' manieristi, ma ad imitazione della scelta natura: tutto è arte, ma tutto è disinvoltura e nascondimento dell'arte. La scuola di Atene in Vaticano è forse in questo genere la più ragguardevole cosa che abbia il mondo." (A tradução para a língua portuguesa é de Ana Maria Santanchè). 
cênica. A mencionada moldura indica uma espécie de ampliação da Porta Central (ou Porta Régia) localizada na skéné do teatro grego da Antiguidade, antecipando a quarta parede, difundida do século XIX como aspecto determinante para o teatro do Realismo.

A Escola de Atenas traz ainda curiosas provocações. Uma delas origina-se na atitude de algumas personagens representadas por Rafael, cujas posturas sugerem movimentos artificializados, deslocados do cotidiano. As posturas apresentadas por essas personagens podem indicar trilhas que seriam seguidas pelos maneiristas, cuja marca incluiria a radicalização de tal abordagem, desinteressando-se pelo argumento explicitado no texto mítico ou bíblico, optando por pesquisar na arte romana antiga e encaminhando sua própria apreensão das fontes. Rafael parecia estabelecer contato direto com o observador através das personagens que fitam quem contempla a obra, rompendo - de certa maneira - as fronteiras da ficção. Tais decisões podem servir como alerta para críticos, comentadores, historiadores e demais interessados na abordagem da obra e das suas relações com supostas fronteiras ou modelos rígidos.

Nos seus aconselhamentos técnicos para o alcance de melhores resultados, Vasari (1993) sugere índices de caráter estilístico, como orgulho, projeto, força, vitalidade, beleza e bella maniera. Artistas que teriam pintado com tal maestria, como Michelangelo e Rafael, são também citados como influência ou ponto de partida para os pintores listados entre os maneiristas. Como especulam Honour e Fleming (1984, p. 378-379), tal classificação derivava dos escritos acerca do comportamento social e da arte do século XVI, quando os especialistas pretendiam caracterizar mais que literalmente estilo ou modo de fazer, e sugeriam virtuosismo, fluência e refinamento, como nos mencionados Rafael e Michelangelo, além de Leonardo. O termo Maneirismo viria a ser aplicado até num sentido pejorativo, para se referir a artistas da segunda metade do século XVI, entre eles Correggio [Antonio Aleggri, (ca. 1489-1534)] e Parmigianino [Francesco Mazzola (1503-1540)]. Aponta-se em Correggio o perigo de um erotismo vulgar, que estabeleceria contradições no tratamento de temas religiosos.

Por outro lado, e isso é importante, ele é tido como o responsável por um novo modelo de ilusionismo na pintura, onde se deve incluir grande habilidade técnica para representar a pele humana, assim como figuras vistas de baixo, e nos movimentos demonstrados pela excelência na representação dos corpos. Comparando a Assunção (da Virgem) em Titian [Tizian, Tiziano Vecelli ou Tiziano Vecellio (ca. 1488/90-1576)] e em Correggio [Antonio Allegri da Correggio (1489 - 1534)] (Figuras 53 e 54), Honour e Fleming (1984, p. 379, tradução nossa) observam: 
[...] um novo tipo de pintura de teto que rompe completamente os limites da arquitetura para abrir uma visão de figuras girando no céu e, por assim dizer, rodopiando com elas, o espectador. Ao invés de testemunhar a cena como se estivesse diante de uma boca de cena (como na Assunção, de Titian), o espectador toma parte nela. ${ }^{4}$

O "espectador" ideal, compreendido em algumas abordagens estético-poéticas como um fruidor, deveria ser partícipe dessa assertiva visual que parece haver permanecido em repouso durante séculos no teatro efetivamente emoldurado pela boca de cena. Quando a diversificada ruptura com o realismo deseja desconstruir o limite palco-plateia, pode indicar um gérmen criado por um artista como Corregio, séculos atrás.

O mencionado tratamento maneirista dos corpos apresenta a deformação provocada pelo alongamento e/ou pela torção inesperada como outro aspecto que merece atenção. Ficam sugeridos corpos e movimentos artificializados, derivados de uma "ideia" particular de corpo, mais uma abstração do que uma representação que toma a natureza como modelo. A tendência ganhou intrigante expressão em El Greco [como assinava Doménikos Theotokópoulos (1541-1614)], em cuja obra a crítica encontrou características do Maneirismo. A Adoração dos pastores revela personagens míticas impregnadas por uma luz divina, enormes figuras que desconstroem a gravidade. A figura do Cristo criança recebeu um tratamento singular ao incorporar uma intrigante luz própria. Configura-se um mundo de brilhos derivados de pedras preciosas, no qual reinam as qualidades cromáticas do ouro, da prata, e do fogo (Figura 55).

Também segundo Honour e Fleming (1984, p. 387), quando Michelangelo teve seu Juízo final (1534-1541) condenado pelo pensamento da Contrarreforma, El Greco afirmou ser capaz de criar obras com maior decência e virtude, capazes de provocar fervor religioso e colocar o espírito dos fiéis acima da realidade sensível do cotidiano. Em A ressurreição [La resurrección (ca. 1597-1600)] pode-se esboçar alguma aproximação entre sua pintura e o Maneirismo, observando o alongamento que já aparece verticalizando artificialmente as personagens; além disso, as imposições narrativas originadas nos escritos bíblicos parecem se dissipar. Note-se que a tumba não é sequer representada, as relações espaciais são artificializadas e a luz

4 "[...] a new type of ceiling painting which breaks completely through the architecture to open a vision of figures swirling into the heavens and, as it were, whirling the spectator into the vortex with them. Instead of witnessing the scene as if through a proscenium arch (as in Titian's Assumption) the spectator is made part of it." 
não inclui parâmetros da natureza. Tais características dão à sua obra grande relevância no estudo da visualidade como aspecto do pensamento daquele período.

Outros artistas podem ser lembrados quando se acentua a contribuição do objeto artístico para o pensamento em questão. Parmigianino [Girolamo Francesco Maria Mazzola (1503-1540), também conhecido como Parmigiano] empenha-se para que sua obra que retrata a mãe de Cristo com o filho desperte a atenção do observador já no título: Madona com longo pescoço [Madonna dal collo lungo (ca. 1535)] (Figura 56). Não somente o pescoço da mãe de Cristo parece estranhamente alongado, mas também a figura do próprio filho de Deus em seu colo. É uma imagem com tratamento inesperado das proporções convencionais. E ainda é difícil apreender a presença da minúscula figura, na extremidade inferior direita do quadro, o que acentua a estranheza da obra. Destaque-se também, o seu Autorretrato em espelho convexo [Autoritratto entro uno specchio convesso, (1623-1624)], como exemplo de tal dissonância (Figura 57).

Apontado como um momento da história da arte cuja compreensão apresenta desencontros nas interpretações, o período deixou traços importantes para sua aproximação com o Barroco, movimento de grande representatividade na práxis cênica. O combate renascentista à teocracia que havia imperado desde o século VII até o século XV incorporou um renovado trato artístico dos temas religiosos, ainda que representando-os como algo distante do público, para ser contemplado "de fora", acentuando-se o papel do observador. As figuras representadas nos quadros eram arquétipos de uma beleza ideal, calculada. Na cena, o uso da perspectiva e o advento da boca de cena que a emoldurava contribuíram para efetivar tal relação. Os eventos sociopolíticos, as ameaças ao poder da Igreja católica, indicam os caminhos mencionados acima, reconhecendo a força do ofício do artista. A Contrarreforma católica demanda uma expressão artística que aproxime as entidades religiosas do homem comum, do fiel; as personagens devem parecer familiares, indicando vida, movimento. O Maneirismo já parece incorporar tais características, antecipando a explosão setecentista. O caráter de grande tensão e movimento que se observa em Assunção da Virgem [Assunzione della Vergine (1526-1530] de Correggio, revelando corpos que parecem girar, expressando deslocamento, é um bom exemplo. Os mesmos Honour e Fleming (1984, p. 379, tradução nossa), citados acima, dizem: "A habilidade de Correggio para representar figuras vistas de baixo (sotto-in-sù ${ }^{5}$, mostrando membros superiores e inferiores muito convin-

5 Traduzido como "visto de baixo" ou "de baixo para cima", a técnica foi aplicada por Mantegna em afrescos pintados na Camera degli Sposi no palácio ducal em Mântua, em 1473. A técnica inclui a representação em escorço, que sugere um ponto de vista extremo e cria uma espécie de deformação do objeto representado. 
centes enquanto giram no espaço, estabelecem um novo modelo de ilusionismo". ${ }^{6}$ Tal consideração demonstra os estreitos laços do Maneirismo, tanto com a Alta Renascença, de onde teria se originado, quanto com o Barroco, para o qual aponta.

\section{CORPORIFICAÇÃO EM VISUALIDADE E MOVIMENTO}

Quando se observa o século XVII cabe atenção às grandes reviravoltas que incluíam o deslocamento de um poder que perdurara por aproximadamente 400 anos, entre 600 d.C. e 1000 d.C., com a teocracia estabelecida sob a autoridade do Sagrado Império Romano, cuja unificação teve como decisivo ingrediente o catolicismo, na condição de religião oficial. A reforma alemã em ascensão, a Guerra dos 30 Anos (1618-1648), o declínio espanhol, que enfrentou rebeliões nos Países Baixos, a presença do parlamentarismo na Inglaterra, o pensamento francês em Descartes, resultaram em mudanças significativas na Europa. Certos eventos produziram grande eco ou representaram estágios do processo de construção de modos de pensar, tanto nas artes visuais, quanto na música, e também nas artes cênicas.

O interesse renascentista em selecionar, calcular e representar matematicamente o mundo, como resultado do posicionamento rigidamente definido por regras geométricas que submetiam a vida ao olhar humano, provocaria reações radicais. O reconhecimento da visualidade como aspecto relevante para a aproximação com Deus e com os santos, como instrumento na construção e na manutenção da fé revela uma Igreja católica que assume, não somente a eficiência da imagem, mas também o desejo do fiel de ver o objeto de sua veneração e adoração. É relevante no presente momento da discussão sublinhar o reconhecimento do apelo que uma imagem pode produzir, mencionando exemplos efetivos dos compromissos estabelecidos pela Igreja, entre o catolicismo e a arte.

As repercussões de tal reconhecimento deram ao teatro do Barroco uma característica importante: nunca antes foram aplicados tantos recursos financeiros no teatro; a compreensão barroca da importância da imagem levava alguns aristocratas a investirem mais no teatro que no exército, a ponto de se aproximarem da ruína econômica, provocada também pelos altos gastos de um teatro exuberante (ágil nas trocas de cenários) e, portanto, fascinante. Isso permitia e suscitava cons-

6 "Correggio's skill in depicting figures seen from below - sotto-in-sù is the technical term - displaying wellturned limbs as they gyrate in space, set a new space for illusionism." 
tantes mudanças, por vezes a cada década, para garantir e ampliar a eficiência do discurso visual; tais mudanças foram rapidamente difundidas por toda a Europa.

Aqui deve ser destacado o fator de regulamentação para a produção artística que responde aos pressupostos do Barroco, as decisões do Concílio de Trento, em particular aquelas que aparecem no documento produzido na $24^{\mathrm{a}}$ sessão, realizada nos dias 3 e 4 de dezembro de 1603 . Parte das decisões já estava indicada no subtítulo Sobre a invocação, veneração, relíquias e santos, e sobre imagens sagradas (On the invocation, veneration, and relics, of saints, and on sacred images):

O santo Sínodo ordena a todos os bispos e outros que mantêm o ofício e a responsabilidade de ensinar de acordo com a prática da Igreja Católica Apostólica [...] que eles especialmente instruam os fiéis sobre a diligente intercessão e invocação dos santos, a honra devida às relíquias e o legítimo uso de imagens [...].

[...] pois a honra que a eles é devotada refere-se aos protótipos representados por tais imagens; desse modo, através das imagens, que beijamos e diante das quais descobrimos a cabeça e nos prostramos, nós adoramos Cristo e veneramos os santos, a cuja semelhança elas são feitas: assim, atendendo aos decretos dos Conselhos, e especialmente do segundo Sínodo de Niceia, ficou deliberada (ação) contra os que se opõem às imagens [...].

[...] E os bispos devem cuidadosamente ensinar que, por meio das histórias dos mistérios da nossa Redenção, retratados através de pinturas ou outras representações, o povo é instruído, confirmando (no hábito de) lembrar, e revolvendo de modo contínuo na mente os artigos de fé; assim também, esse grande proveito é derivado de todas as imagens sagradas, não só porque as pessoas são, desse modo, alertadas acerca dos benefícios e dons a eles concedidos por Cristo, mas também porque os milagres que Deus realizou por meio dos santos, e seus exemplos salutares, são apresentados diante dos olhos dos fiéis [...]. ${ }^{7}$ (THE COUNCIL..., 1848, p. 233-235, grifo e tradução nossos)

\footnotetext{
7 "The holy Synod enjoins on all bishops, and others who sustain the office and charge of teaching, that, agreeably to the usage of the Catholic and Apostolic Church, [...] they especially instruct the faithful diligently concerning the intercession and invocation of saints; the honour (paid) to relics; and the legitimate use of images [...] because the honour which is shown them is referred to the prototypes which those images represent; in such wise that by the images which we kiss, and before which we uncover the head, and prostrate ourselves, we adore Christ; and we venerate the saints, whose similitude they bear: as, by the decrees of Councils, and especially of the second Synod of Nicaea, has been defined against the opponents of images. [...] And the bishops shall carefully teach this, - that, by means of the histories of the mysteries of our Redemption, portrayed by paintings or other representa-
} 
Dois aspectos devem ser destacados, uma vez que exercem impacto sobre o discurso visual: a confiança no movimento e na proximidade com a natureza dos corpos. Esse desejo de movimento e de irromper nos domínios daquilo que se acreditava real, buscava a representação dos corpos à semelhança daqueles encontrados no cotidiano. A despeito do tema sendo pintado, do grau de fantasia da história sendo contada, da acentuada saturação e fortes traços estilísticos, o tratamento da musculatura e da pele [sublinhado pelos críticos como um recurso que as aproximava da aparência humana]. O movimento e a similaridade visual com o real se fez presente no Barroco - num sentido específico - quando os artistas incorporaram o desejo de aproximar o espectador da obra que contemplava.

Incorporando à discussão a necessidade barroca de movimento e de expressão da natureza humana, aqui será incluída a obra de Michelangelo Merisi da Caravaggio (1571-1610). Na sua pintura Ceia em Emaús [Cena in Emmaus (1601)] encontram-se aspectos que sublinham as relações entre a visualidade - na qual se incluem entrelaçamentos entre visibilidade e cultura - e a cena (Figura 58). Os principais registros com os quais Caravaggio contava na elaboração desta obra estão no Novo Testamento, em particular nos evangelhos de Marcos e Lucas:

13 Nesse mesmo dia, dois deles estavam de caminho para uma aldeia chamada Emaús, que distava de Jerusalém sessenta estádios; ${ }^{14} \mathrm{E}$ iam conversando a respeito de todas as coisas sucedidas. ${ }^{15}$ Aconteceu que, enquanto conversavam e discutiam, o próprio Jesus se aproximou e ia com eles; ${ }^{16}$ Os olhos deles estavam como que impedidos de o reconhecer. ${ }^{17}$ Então lhes perguntou Jesus: Que é isso que vos preocupa, e de que ides tratando à medida que caminhais? E eles pararam entristecidos. ${ }^{18} \mathrm{Um}$, porém, chamado Cleopas, respondeu dizendo: És o único porventura, que, tendo estado em Jerusalém, ignora as ocorrências destes últimos dias? ${ }^{19}$ Ele lhes perguntou: Quais? E explicaram: O que aconteceu a Jesus, o Nazareno, que era varão profeta, poderoso em obras e palavras diante de Deus e de todo o povo. ${ }^{20}$ e como os principais sacerdotes e as nossas autoridades e entregaram para ser condenado à morte, e o crucificaram. ${ }^{21}$ Ora, nós esperávamos que fosse ele quem havia de redimir a Israel; mas depois de tudo isso, é já este o terceiro dia desde que tais coisas sucederam. ${ }^{22}$ É verdade tam-

tions, the people is instructed, and confirmed in (the habit of) remembering, and continually revolving in mind the articles of faith; as also that great profit is derived from all sacred images, not only because the people are thereby admonished of the benefits and gifts bestowed upon them by Christ, but also because the miracles which God has performed by means of the saints, and their salutary examples, are set before the eyes of the faithful; [...]." 
bém, que algumas mulheres, das que conosco estavam nos surpreenderam, tendo ido de madrugada ao túmulo ${ }^{23}$ e, não achando o corpo de Jesus, voltaram dizendo terem visto uma visão de anjos, os quais afirmam que ele vive. ${ }^{24}$ De fato, alguns dos nossos foram ao sepulcro e verificaram a exatidão do que disseram as mulheres; a ele, mas não o viram. ${ }^{25}$ Então, lhes disse Jesus: ó néscios, e tardos de coração para crer em tudo o que os profetas disseram! ${ }^{26}$ Porventura, não convinha que o Cristo padecesse e entrasse na sua glória? ${ }^{27} \mathrm{E}$, começando por Moisés, discorrendo por todos os Profetas, expunha-lhes o que a seu respeito constava em todas as Escrituras. $\left.\right|^{28}$ Quando ele fez menção de passar adiante. ${ }^{29}$ Mas eles o constrangeram, dizendo: Fica conosco; porque é tarde, e o dia já declina. E entrou para ficar com eles. ${ }^{30} \mathrm{E}$ aconteceu que, quando estavam à mesa, tomando ele o pão e o abençoou-o e, tendo-o partindo, lhes deu. ${ }^{31}$ então, se lhes abriram os olhos, e o reconheceram; mas ele desapareceu da presença deles [...]. ${ }^{8}$ (BÍBLIA, 1999, p. 1223-1224)

Marcos, em 16-12, relatou: "[...] [Jesus] manifestou-se em outra forma a dois deles que estavam de caminho para o campo". (BÍBLIA, 1999) Caravaggio construiu sua versão fazendo assertivas visuais contundentes. É notável o seu desejo de revelar naqueles apóstolos a semelhança com pessoas que se podia efetivamente encontrar numa estalagem, sentados à mesa comendo frutas, uma ave e pão. Se o homem de pé, à esquerda de Cristo, parece imobilizado, isso reflete o apelo que o último exerce. Outros reagem às palavras e atos de Jesus, como a uma força que os arrebatou.

Há um grau explícito de tensão, como se fosse possível reter efetivamente na pintura um fragmento do ocorrido. Num certo sentido, o observador pode ser surpreendido a qualquer momento e testemunhar aqueles homens "saindo" do quadro, projetando-se, escapando e continuando a ação fora do plano da obra artística. A bandeja, à direita, em primeiro plano, pode cair a qualquer instante. Tal conjunto de aspectos produziria uma aproximação com a pessoa que contemplasse a imagem, levando-a a interagir com todo o seu corpo. Caso estivesse muito perto da imagem ela talvez precisasse prover espaço para permitir que os homens envolvidos na ação se deslocassem e até, talvez, fosse surpreendida por um movimento brusco sendo tocada por uma daquelas figuras.

8 Os números em sobrescrito que aparecem nessa citação não se referem a notas específicas desta tese, mas representam a subdivisão dos capítulos no texto de Lucas. 
Alguns comentadores consideram que o Cristo pintado por Caravaggio parece muito jovem, se comparado com o homem de longas barbas que as artes visuais difundiram ao longo da história da pintura religiosa. Outros veem traços femininos na composição da personagem. Observando o texto bíblico, podemos notar já no apóstolo Lucas que os homens não o podem reconhecer. No breve texto de Marcos, tomamos conhecimento que Cristo "[...] manifestou-se em outra forma [...]". (BÍBLIA, 1999, p. 1178) Aí, tanto em Lucas quanto em Marcos, Caravaggio se deixa provocar e reage como um artista próximo da Alta Renascença que arremessa adiante sua poética.

\section{A LUZ COMO ELO ENTRE A PINTURA E A CENA}

Caravaggio trabalhou com uma arte religiosa na qual a representação da divindade e dos santos incorporava concretude e semelhança humana. Além disso, ele introduziu um tratamento exemplar do ambiente onde cada evento ocorria. A retórica maneirista elaborada através de "figuras de arte" artificializadas e distanciadas cede espaço à necessidade de contato com o observador. Caravaggio propôs um modo inovador de incluir as relações entre luz, penumbra e sombra na arte pictórica. Se as suas figuras míticas assemelham-se a outras que poderiam ser encontradas no dia a dia, por outro lado, ele as mergulhava num mar de trevas, criando intrigantes contrastes que revelavam a força expressiva de cada uma das personagens e, por conseguinte, da ação inscrita na imagem.

Não é raro encontrar comentários que classificam sua pintura como exemplo de aplicação "dramática" da luz, referindo-se ao apelo emocional da imagem, além de uma assertiva visual que impulsiona sua obra na direção da cena, considerando-se que suas pinturas sugerem fragmentos-chave de espetáculos, fragmentos cuidadosamente selecionados como núcleo visual de uma ação cênica que contém movimentos passados e que se projeta no futuro. Para o iluminador, a obra de Caravaggio pode indicar relevantes objetos de pesquisa, investigando-se o rigor aplicado por ele na busca de excelência para suas imagens. Independente de estilos, poéticas e revoluções, rigor e excelência na criação da imagem integram (ou deveriam integrar) a práxis cênica.

Waldemar Januszczac ${ }^{9}$ afirma que durante a Contrarreforma a pintura se esforçou por atender à indicação ou exigência da Igreja Católica, para a qual o objeto artístico deveria ganhar a atenção do católico e convencer os infiéis. Ele acrescenta:

9 Crítico de arte inglês, nascido em 1954, escreve no Guardian e no Sunday Times. 
"[...] um truque muito eficiente é usar dramaticamente a escuridão e transformar a pintura em teatro". ${ }^{\circ}$ (BAROQUE..., 2009, tradução nossa) O termo "truque" pode dar lugar a interpretações negativas e/ou pejorativas e talvez fosse preferível dizer estratégia ou procedimento, notando-se em Caravaggio caminhos que estabelecem uma visualidade repleta de atmosferas, mergulhando a ação nas sombras, alcançando níveis de precisão com altíssimo grau de dificuldade para sua efetivação no teatro, seja considerando o estágio técnico da luz aplicada àquele tempo, na cena, ou a escassez de treinamento específico, hoje em dia. O grau de controle da intensidade, da cor, da distribuição dos aparatos que determina os ângulos e da dimensão do foco apresentado pela sua pintura só seria alcançado séculos mais tarde, com o advento da luz elétrica. Foi necessário o aparecimento de outra qualidade tecnológica dos instrumentos aplicados na produção de luz artificial, assim como dos sistemas de controle e dos acessórios, para que se pudessem alcançar na cena resultados próximos daqueles já vislumbrados por Caravaggio, séculos antes da aplicação da eletricidade como recurso para a luz artificial.

Depois de ter visto obras com tal proporção, o olhar moderno ganhou a oportunidade de aproximar-se de imagens com qualidade semelhante também na cena, desde os finais do século XIX, e pode ter assumido que elas sempre lá estiveram. A observação atenta e a reflexão cuidadosa provam o contrário, o que torna a obra de Caravaggio objeto relevante de estudo, apontando possibilidades de contato entre a abordagem cênica da luz e as artes visuais, principalmente a pintura.

O contato com Caravaggio leva a abordagens que se originaram no Barroco, ligadas ao fervor de um pensamento religioso que busca aproximar a narrativa das artes visuais de cada fiel, de cada um que contempla uma obra. A incorporação da "verdade", no sentido de semelhança com o real observado no cotidiano e da sugestão de movimento, que sugere a presença do corpo vivo, é um dos aspectos mais determinantes do Barroco. Tudo isso, por outro lado, de acordo com a elaboração particular de cada artista pode sugerir resultados completamente diversificados. Para exemplificar tal possibilidade, cabe observar a obra de outro artista do período, Annibale Carracci (1560-1609), como uma possível transição entre os cânones da Alta Renascença - passando por influências de Michelangelo e Rafael - e o Barroco. Interessa destacar aqui os afrescos pintados pelos Carracci, Annibale e seus irmãos, em 1595, no Palácio Farnese, em Roma, entre os quais O triunfo de Baco e Ariadne [Il trionfo di Bacco e Arianna, imagem central no teto

10 "[...] one very effective trick is to make dramatic use of the dark and turn painting into theatre. A citação foi retirada de um vídeo e, portanto, não possibilita a inclusão de número de página." 
da Galeria (Figuras 59 e 60)]. O conjunto pictórico da Galeria Farnese é conhecido como Os amores dos deuses.

O primeiro biógrafo de Carracci, Giovanni Pietro Bellori (ca. 1615-1696), já aponta a natureza barroca da sua obra e acentua os traços maneiristas, sem o enfoque pejorativo mais tarde associado ao termo. De acordo com Honour e Fleming (1984), essas pinturas apresentam uma espécie de racionalização de Michelangelo, tomando como fonte de inspiração a Capela Sistina. Buscando alcançar o grau de ilusionismo desejado para definir os diferentes níveis de realidade aplicados, a obra de Caracci alcança o grau de ilusionismo desejado, para definir os níveis de realidade envolvidos, e estabelece uma estrutura decorativa, composta da simulação de relevos de gesso e medalhões de bronze, além de estátuas que funcionam como moldura para as pinturas. Importante notar a visualidade diferenciada, quando são comparados os relevos e medalhões, que reagem à luz do ambiente da Galeria, em constante mudança, com a luz fixada nos afrescos.

Além da estratégia do sotto-in-sù já conhecida na Itália àquele tempo, aplicada desde Andrea Mantegna (Figura 61), a técnica da quadratura ${ }^{11}$ foi aplicada por Caracci, incorporando referências à perspectiva, como elo entre pintura e arquitetura, elaborando o convencimento daquele que contempla a obra. Uma policromia particular determina a assertiva visual, estabelecendo o contraste para a identificação dos casos de amor entre os deuses, narrados no interior das molduras. As estátuas mantêm um aspecto de pedra polida, enquanto querubins povoam toda a obra, aparecendo não somente fora das cenas pintadas, como também ingressando no espaço de algumas unidades narrativas. Cada uma das soluções tem relação direta com a aplicação diferenciada da luz e da sua potencialidade cênica moderna, ou seja, o enquadramento da ação pela boca de cena. Tais soluções apresentariam no teatro um elevado grau de dificuldade, devido a limitações de natureza técnica, especialmente na luz. Vale, portanto, incluir a obra de Carraci como mais uma e relevante fonte de pesquisa para a compreensão da luz na cena da modernidade. A afirmação de Honour e Fleming (1984, p. 427-428, tradução nossa) pode contribuir para alargar o horizonte dos estudos do tema:

11 De acordo com Oxford Dictionary of Art, o termo quadratura, originalmente ligado aos três problemas da geometria grega, foi usado no Barroco para caracterizar a técnica ilusionista na pintura, principalmente nos afrescos pintados em tetos de edificações, aplicando a perspectiva. Usado desde a pintura romana antiga, esse procedimento ganha expressão particular no Barroco, provocando ilusão da extensão dos limites arquitetônicos de uma edificação, sugerindo tridimensionalidade inexistente. A técnica da quadratura bolonhesa foi aplicada na pintura de superfícies abobadadas, como os tetos das igrejas ou dos palácios. (CHILVERS, 2004, p. 571, tradução nossa) 
Annibale Carraci não era um teórico, mas seu trabalho viria a ser exaltado como um exemplo de uma versão racionalizada da teoria estética do século XVI, substituindo a 'Ideia' metafísica neoplatônica, um ideal derivado puramente da arte em si mesma. Por mais de dois séculos, ela proveria a base de toda a prática acadêmica. ${ }^{12}$

Trata-se de um caminho que indica outros exemplos de conexão com a cena. Vale destacar O êxtase de Santa Teresa (L'estasi di Santa Teresa), conjunto escultórico inspirado pela narrativa apresentada pela própria Santa Teresa D’Ávila (1515-1582), concebido por Bernini [GianLorenzo Bernini (1598-1680)] a pedido do Cardeal Federico Cornaro (1579-1673), e construído entre 1647 e 1652, na Capela Cornaro - Igreja Santa Maria della Vittoria - em Roma, considerado depois um marco da expressão do Barroco (Figura 62).

No capítulo XXIX de sua autobiografia, Teresa D’Ávila relata uma experiência na qual um belo e pequeno anjo vem ao seu encontro. Sua descrição indica uma aparência em brasa, relacionando o divino à luz e ao fogo. Ele traz um dardo ou seta dourada, cuja ponta parecia em chamas. Penetrada no coração, com as entranhas ferventes e extrema dor espiritual, que repercutia profundamente no corpo, ela teve a alma abrasada pelo amor de Deus.

O que resulta na obra de Bernini é um conjunto de esculturas que representa um teatro dentro da Capela, incluindo uma espécie de palco ao centro, e até camarotes. Em um deles, à direita, aparece o próprio Cardeal Cornaro, acompanhado de membros da sua família, que assistem a um espetáculo. Os membros da plateia (nesses camarotes) guardam traços que configuram um elo com o cotidiano, quando menos destacando expressões de um grupo de espectadores que reagem à ação revelada no "palco", o nicho central. O artista apoia a santa sobre uma nuvem que transcende a gravidade, revelando ao espectador um momento particular de profundo êxtase da jovem Teresa, que paira no céu, penetrada pelo amor divino.

Em uma decisão de natureza significativamente espetacular, Bernini materializa os raios do brilho de Deus com fachos dourados de luz, que se projetam do centro superior, como que inundando o ambiente.

Em muitos espetáculos da atualidade podem ser identificadas semelhantes tentativas de corporificação da luz. De modo primitivo, instrumentos (refletores) posicionados atrás da cena, como se pode ver em circos e ringues de boxe, criam a

12 "Annibale Carraci was no theorist, but his work soon came to be extolled as the exemplar of a rationalized version of sixteenth-century aesthetic theory, substituting for the Neoplatonic metaphysical 'Idea', an ideal derived from art itself. For more than two centuries it was to provide the basis of all academic teaching." 
luz "materializada", "pulverizada" ou "fragmentada", como resultado dos raios que incidem em partículas presentes no ar. Bertolt Brecht (1898-1956) buscou incorporar em suas montagens momentos com tal qualidade.

A tecnologia aplicada à cena, desde o século passado, introduziu equipamentos e acessórios diversos, do tipo máquina de fumaça ou de neblina que umidificam o ar e produzindo a exposição dos fachos de luz oriundos dos instrumentos, pigmentando a fumaça ou neblina de acordo com a cor dos filtros. Em certas "estéticas", o efeito comentado tornou-se uma espécie de norma, sendo seu uso largamente difundido, o que até estabelece o lugar comum de certas regras impostas a uma forma de arte. Num certo sentido, pode-se compreender a tendência como mera repetição ou como "maneirismo vulgar".

O mencionado corpo escultórico, ao centro do conjunto concebido por Bernini, num branco muito brilhante, revela a força da luz que se projeta simbolicamente em sua direção. Se Bernini parece diluir as fronteiras entre escultura e arquitetura, como se pode verificar no baldaquino (baldacchino),,$^{13}$ construído na catedral de São Pedro, na cidade de Roma [(1624-1633, Figura 63)], em O êxtase de santa Teresa, ele elabora imagem provocada pela inexorável parceria que envolve o teatro e a luz. Por conseguinte, pode-se dizer que Bernini indica trilhas dinâmicas, entre as artes visuais e o espetáculo, que serão visitadas por muitos outros artistas, sublinhando a assertiva visual da práxis cênica, assim como a potencialidade cênica das artes visuais.

Afastando o objetivo de um estudo aprofundado do Barroco é importante apresentar aqui uma breve observação do seu extenso e diversificado caráter. Desse modo, buscando acentuar a qualidade atmosférica incorporada pela sua visualidade, o presente capítulo inclui a obra de Andrea Pozzo (1642-1709), pintor, arquiteto e teórico nascido em Trento. O início da sua carreira inclui pinturas cujo tratamento indica relação direta com a estética já sublinhada em Caravaggio. Jodi O’Toole, em dissertação apresentada como requerimento parcial para o título de mestre na McGill University, no Canadá, oferece em breve descrição elementos para tal assertiva: "Essas telas, na sua maioria, decoravam igrejas jesuítas no nordeste e na região central da Itália. O tema de cada tela exigia cenas imersas na escuridão e

13 Numa igreja, uma estrutura ornamental em forma de dossel, apoiada em quatro pilares, usualmente construída para abrigar um altar, e incluindo geralmente estátuas e relevos decorativos. (THE OXFORD..., 2004, p. 47, tradução nossa) 
iluminadas por luz controlada, frequentemente através do uso de velas ou tochas ${ }^{\prime m 4}$ (O’TOOLE, 1999, p. 9, tradução nossa) (Figura 64).

Andrea Pozzo segue caminho semelhante àquele escolhido por Caravaggio e pode-se verificar a antecipação empreendida por ambos, quando eles se debruçam sobre a expressão da visualidade controlada e deixam uma provocação para as artes cênicas, uma vez que, como já foi dito, tal controle da luz permanecerá um desafio técnico só efetivamente atingido através da aplicação da luz elétrica. O teatro foi obrigado, portanto, a esperar alguns séculos até que nele se pudesse elaborar - no seu modo tridimensional - a afirmação visual já observada em artistas como Pozzo e Caravaggio, além de outros que se seguirão, alguns deles aqui mencionados. Vale verificar, então, que a práxis cênica pode ter experimentado um extenso aprendizado por centenas de anos.

Pozzo, que trabalhou na elaboração de eventos para a ordem dos jesuítas, como arquiteto e cenógrafo, incluiu na sua obra o trabalho teórico Perspectiva para a pintura e para a arquitetura (Perspectiva pictorum et architectorum), em dois volumes ilustrados, publicados, respectivamente em 1693 e 1698, como instrução para artistas que trabalhavam com a arquitetura e também com a cenografia. Esses livros estão entre os primeiros manuais de perspectiva que se conhece, na trilha do trabalho de Leon Batista Alberti, já citado, e foram traduzidos para vários idiomas, inclusive o chinês. Note-se que o trabalho teórico de Pozzo inclui plantas, elevações, cortes e perspectivas de um teatro, apresentando a organização espacial do palco barroco, ainda que a plateia pareça mais ligada a princípios originados no teatro romano, e já aplicados no início do Renascimento por Andrea Palladio no projeto do Teatro Olímpico, em Vicenza, citado e comentado no capítulo anterior do presente texto. Tal característica do espaço destinado ao público pode justificar a ponderação de Allardyce Nicoll (1927, p. 138), quando diz que, apesar de publicados em 1692, os desenhos foram realizados muitos antes do período em discussão (Figura 65).

De um ângulo que pode ser considerado extremo na obra de Andrea Pozzo, quando comparado a suas telas contempladas acima, que mergulhavam nas trevas, deve ser destacado o afresco realizado no teto da igreja jesuíta de Santo Inácio, ${ }^{15}$ em Roma, entre 1685 e 1694. Quando começou a execução da obra em questão,

\footnotetext{
14 "For the most part, these canvases decorated Jesuit churches throughout northern and central Italy. The subject matter of each canvas demanded scenes immersed in darkness with controlled lighting. Often by candle light or torch."

15 A Igreja de Santo Inácio foi construída entre 1626 e 1650, para celebrar a canonização de Inácio de Loyola, em 1626, fundador da Companhia de Jesus, com projeto de Orazio Grassi (1583-1654).
} 
Pozzo já pertencia à ordem jesuíta há vinte anos, na qual havia ingressado em 1665 . Denominado Apoteose de Santo Inácio, o afresco é destacado como sua obra-prima, e um dos principais exemplos de ilusão perspectivista até sua época, além de ser considerado importante demonstração de movimento impregnado de grandiosidade, traço determinante no Barroco. O observador deve posicionar-se sobre um disco de bronze, disposto no piso da nave da igreja, para mergulhar na ilusão de tridimensionalidade, experimentando assim o "desaparecimento" da superfície plana do teto que parece se abrir numa multiplicidade de acontecimentos, celebrando os feitos missionários dos jesuítas (Figura 66).

Pozzo teria declarado que a narrativa por ele criada se derivava do evangelho de Lucas, 12:49: "Eu vim para lançar fogo sobre a terra e bem quisera já estivesse a arder". (BAROQUE, 2009) No afresco, a luz emana de Deus Pai, em direção ao Cristo, que a lança para Santo Inácio. Esse, por sua vez, projeta a luz divina para todos os cantos da Terra, representados pelos quatro continentes, numa alusão à ideologia jesuíta. Do ponto de vista filosófico, a obra empregou a compreensão da luz como instrumento para difundir a fé católica, como fonte de conhecimento. A aparente complexidade cênico-visual da imagem criada por Andrea Pozzo, apresentando imensa profundidade numa superfície plana, encontra unidade na contribuição da luz, elaborando visualmente o pensamento político-religioso que fundamenta a narrativa.

Aqui também a pintura deixou impulsos para a visualidade da cena, não somente no teatro, mas também, posteriormente, no cinema. O manual escrito por Pozzo deixou exemplos de procedimentos largamente utilizados por cenógrafos e mestres em efeitos especiais, desde aquele momento até os nossos dias. Waldemar Januszczak, já citado, tece um comentário onde dá conta que Cecil B. de Mille (1881-1959) teria consultado a obra de Andrea Pozzo durante a elaboração dos seus filmes bíblicos. (BAROQUE, 2009)

A interação entre estudos teóricos, a pintura, a arquitetura, a ilusão e a cena, alcança em Pozzo um ponto que se reproduziria por toda a história do espetáculo e, já no Barroco, provocava exclamações de espanto dos espectadores e o interesse de especialistas. Em meio a tal efervescência visual, a cena barroca incorporou ensinamentos da técnica renascentista, como registrado por Sabbattini e Furttenbach. Certos aspectos, no entanto, merecem destaque na sua condição de elementos introduzidos pelo teatro do século XVII. Em primeiro lugar, a nova tipologia espacial do teatro exige modos diferentes de elaboração e ocupação do espaço cênico. A disposição preponderantemente horizontal do modelo renascentista modifica-se, ao ganhar o incremento da profundidade do palco, apontando inclusive para uma 
nova atitude do ator (ou do performer). Além disso, o tratamento desse novo espaço de acentuada profundidade encaminha uma nova estética cenográfica, em parceria com a perspectiva e, inevitavelmente, com a luz.

\section{TEATRO NO BARROCO E TIPOLOGIA ESPACIAL}

De acordo com Gösta M. Bergman (1977), o modelo do espaço teatral barroco apresentava casas de espetáculo nas quais a profundidade da caixa cênica chegava a representar uma dimensão três vezes maior que a sua largura, incluindo os bastidores. Ele compara o teatro italiano do período com aquele que se praticava na França, e comenta a atitude francesa na qual os eventos teatrais funcionavam também como um meio de relações sociais, incluindo conversas e sedução. O espectador ia ao teatro não somente para ver, mas também para ser visto. Tanto a Opéra, em Paris, quanto a Comédie Française serviam como um grande salão para abrigar festividades nas quais os membros da plateia se comunicavam efusivamente, inclusive em camarotes abertos. Segundo Bergman (1977, p. 89, tradução nossa), foi estabelecido na Itália um comportamento diferenciado:

Aqui se encontrava a vitória de um novo princípio óptico com uma nova espécie de edifício teatral: a imensa plateia com suas fileiras uniformes de camarotes, uma sobre a outra, imersa numa misteriosa escuridão ou semiescuridão, sendo a luz concentrada no palco. Essa diferença da luz era a marca de excelência dos teatros italianos, durante os séculos XVIII e XIX. ${ }^{16}$

Na França, desde o final do século XVI, a corte realizava deslumbrantes espetáculos de balé, no Petit Palais Bourbon. A tecnologia vista na Renascença italiana podia ser também encontrada em Paris, no mesmo período. O grande salão que recebeu o Ballet comique de la reine, em 1581, foi inteiramente iluminado para revelar o brilho dos cenários e figurinos e celebrar o rei em toda a sua glória e poder.

Desafortunadamente, os documentos que se referem aos espetáculos de balé na corte francesa não contêm detalhes sobre os arranjos da luz. Em espaços usados para festividades, o padrão era estabelecido na necessidade de iluminar todo o ambiente. Sabe-se que na grande Salle du Louvre, durante o Ballet du duc Vendome,

16 "Here is to be found the victory of the optical principle with a new type of theatre building, the box and circle theatre: the huge auditorium with its huge tiers of boxes, one above other, lay in a mysterious darkness or semi-darkness, the light being concentrated exclusively on stage. This differentiation of the light was to be the hallmark of the public Italian theatres during the 18th and 19th centuries too." 
em 1610, 1600 candelabros e tochas transformaram o espaço teatral numa orgia de luz. Tal aplicação da luz diverge da proposição cênica que a antecede na Itália.

O correspondente do Mercure galant, ${ }^{17}$ Chassebras de Cramailles (dados biográficos não identificados), destacou o Teatro San Giovanni Grisostomo como o maior e o mais belo de Veneza naquele momento e comentou que uma hora antes do início do espetáculo uma pintura de Vênus era deslocada no teto (plafond), e, por uma grande abertura, descia um candelabro que media aproximadamente quatro metros de altura, iluminando a plateia e sendo levantado momentos antes do início da performance.

A cena era construída em perspectiva num espaço seletivamente iluminado que alcançava desde 30 e 40 quarenta metros de profundidade. Bergman (1977, p. 99, tradução nossa) pondera: "O sistema normalizado de luz, com aparatos dispostos acima do espaço cênico e nas laterais, codificados por Sabbattini e Furttenbach, pode muito bem ter sido adaptado para o palco barroco, cada vez mais profundo". ${ }^{18}$ A mobilidade promovida pelos sistemas instalados sob o palco para as mudanças de cenários, assim como os intricados elementos aéreos como nuvens repletas de personagens, um céu que se abria e fechava - representavam uma convenção na qual a luz desempenhava papel decisivo. Tal apelo ao movimento sugere parceria com a luz, acentuando-se a aplicação de brilhos e transparências.

Contando com ilustrações relativas ao trabalho de Giacomo Torelli (16081678) e projetando a repercussão de trabalhos como os de Serlio, Sabbattinni e Furttenbach, pode-se imaginar a provocação exercida pelas proposições visuais do Barroco sobre artistas responsáveis pela visualidade da práxis cênica. Bergman (1977) afirma que a grandiosidade presente na obra de Torelli, considerando como exemplo Bellerofonte (Veneza, 1642), será até suplantada, como se pode observar em A Idade do ouro (L'etá dell-oro), balé apresentado em Parma (1690), no Palácio da Virtude: "[...] [um palácio] construído em gigantescas dimensões flutuava sobre a cidade preenchendo grande parte do cenário". ${ }^{19}$ (BERGMAN, 1977, p. 101, tradução nossa)

Enfrentando limites importantes para a produção de luz artificial originada na combustão, através de velas, tochas e lamparinas, os arquitetos e artistas plásticos

\footnotetext{
17 Periódico francês, fundado em 1672 por Donneau de Visé. Inicialmente publicado em intervalos regulares, passou a edições mensais, em 1678.

18 "The normalized lighting system with advanced overhead, under and side light, which had been codified by Furttenbach could very well be adapted to the more and more deepened baroque stage."

19 "[...] built on a gigantic scale, floated above the town filling the greater part of the set."
} 
que se aventuravam na empreitada de revelar a cena lidavam com a dificuldade de controle sobre tais fontes. De todo modo, os artistas procuravam tirar o maior partido possível das características das fontes de luz artificial e sua relação com os aspectos arquitetônicos dos espaços teatrais, apresentando soluções que impressionavam o público da época. Parece óbvio que definir a dimensão do facho, assim como o direcionamento da luz eram tarefas quase impossíveis, naquela época, quando se compara à tecnologia aplicada aos instrumentos disponíveis, depois do advento da luz a gás e, principalmente, da luz elétrica, dado o enorme progresso tecnológico que resultou em controle e grande precisão.

O teatro do Barroco entendeu visualmente tal limitação e deu respostas diversificadas, acentuando o modelo espetacular de movimento mecânico aplicado à cenografia, incorporando a luz produzida por fontes dispostas longe do alcance do olhar do espectador, adotando o bloqueio da luz através de aparatos cujo princípio já estava presente no dimmer de Serlio, adicionando cor - prática também desenvolvida no Renascimento -, e aplicando a fantasia proporcionada pelos fogos de artifício, já largamente usados nas festividades medievais. Pode-se presumir que variada estratégia foi aplicada para interagir com as técnicas da produção de luz artificial mencionada, cujos avanços significativos tardaram a aparecer.

Ainda assim, as tapadeiras que se moviam, não somente em sentido paralelo à boca de cena, mas também em movimentos diagonais, assim como a aplicação maciça de grandiosos elementos aéreos, representaram mudanças importantes para a visualidade no teatro do século XVII. Incorporavam-se, também, provocações decorrentes das festividades medievais que se encontraram com o desejo de grandeza do pensamento barroco, juntando-se a isso uma incessante busca pelo movimento.

O principal nome mencionado, quando se trata dos passos desbravadores das tendências do barroco, é o de Giacomo Torelli. Pouco se conhece da vida de Torelli, antes da sua notoriedade no teatro. Nascido em Fano, de origem nobre, recebeu provavelmente educação inerente a sua posição social, ainda que não haja registro referente à sua formação no teatro. O jovem Torelli mostrou talento natural para a arquitetura, a pintura e a cenografia, e alguns comentadores até especulam que ele teria sido orientado por Niccola Sabbattini, o que seria plausível, uma vez que a distância entre Fano e Pesaro é de quarenta quilômetros. Em 1637, Torelli projetou cenários para as performances apresentadas entre os atos (intermezzi) da Pastoralle, de Ridolfo Campeggi, onde demonstrou sua habilidade para os projetos de cenotécnica que possibilitaram grande eficiência na mecânica aplicada às mudanças da cena. 
Graças à reputação alcançada na sua cidade natal, Torelli mudou-se para Veneza, aos 33 anos, convidado pela Accademia degli incogniti, uma sociedade de muito prestígio, na qual encontrou seu primo Vincenzo Nolfi. Lá, ele recebeu da academia a incumbência de construir um teatro. Em 27 de janeiro de 1641, Torelli inaugurou o Teatro Novíssimo e assinou a cenografia de A falsa louca (La finta pazza), com música de Francesco Sacrati (1605-1650) e libreto do acadêmico Giulio Strozzi (1583-1652) (Figura 67). Torelli desenvolveu um sistema de mudança de cenários baseado no uso de contrapesos, o que contribuiria para torná-lo famoso em toda a Europa. O Teatro Novíssimo trazia essa inovação: o palco apresentava cortes laterais no piso, em cada coxia, que funcionavam como trilhos ou guias, para tapadeiras que eram movidas lateralmente, revelando novos ambientes, de acordo com cada momento.

As tapadeiras planas foram provavelmente introduzidas por Giovanni Battista Aleotti (1546-1636), como elemento cenográfico no qual se pintavam partes do cenário de um espetáculo e, dispondo de várias tapadeiras, uma atrás da outra, estabelecia-se a possibilidade de mudanças rápidas e diversificadas na cenografia. Tal solução se transformaria num passo decisivo para a operação dos cenários simétricos, aplicando a perspectiva com um ponto de fuga ao centro da imagem, modelo aplicado naquele período, ainda que apresentasse a desvantagem de exigir um maquinista para cada unidade do sistema a ser operada. Desafortunadamente, para a história do teatro, o Novíssimo foi atingido pelos resultados econômicos da guerra turca, e nunca mais reaberto depois de 1647.

Apesar do breve período de operação, contudo, ele ficou reconhecido como o único teatro de Veneza, na época, que incorporava paralelos com as salas de Bolonha e Florença. Além disso, sua iniciativa de entretenimento principesco, sem a exigência de resultados financeiros, em primeiro plano certamente contribuiu para a experimentação desenvolvida por Giacomo Torelli, suscitando novos padrões de magnificência para a ópera. As soluções técnicas implantadas por Torelli permitiam movimentação simultânea de conjuntos de tapadeiras, operando a mudança total no cenário, de modo rápido e sincronizado (Figura 68). O sistema espalhou-se pelos teatros de toda a Europa, fazendo Torelli ficar conhecido como "mago da cena". (KIMBLE, 1995, p. 115) É plausível reconhecer o importante papel desempenhado pela luz para revelar essa qualidade mágica.

Alguns especulavam que ele havia acordado um pacto com o demônio. A documentação acerca de sua obra, incluindo a iconografia por ele produzida, não revela de modo específico as relações com a luz. No entanto, considerando as características do novo palco barroco, às quais estava associada a grandiosidade dos cená- 
rios de Torelli, é possível indicar um significativo grau de relações dessa natureza. Algumas gravuras do período retratam espetáculos como Bellerofonte (1642), libreto de Vincenzo Nolfi; La venere gelosa (1643), libreto de Niccolo Enea Bartolini, Deidamia, de Scipione Herrico, no Teatro SS, Giovanni e Paolo, além de Ulisse errante, de Giacomo Badoaro, em (1644). Ainda que as gravuras não representem exatamente a maneira como as cenas aconteceram, principalmente do ponto de vista das cores, elas sugerem parcialmente o tratamento visual dos espetáculos citados. O projeto de Torelli para o Teatro della Fortuna, inaugurado na sua cidade natal, em 1667, mostra esquematicamente a disposição simétrica das tapadeiras (Figura 69).

Outro documento do século XVII, que tem papel relevante para a compreensão técnica dos espetáculos da época, é o diário de viagens escrito por Nicodemus Tessin, o jovem (1654-1728). ${ }^{20}$ Elaborado entre 1687 e 1688, o texto inclui no segundo volume relatos acompanhados de desenhos acerca do aparato cênico que Tessin teria encontrado em Veneza, registrando impressões de espetáculos e teatros característicos do Barroco. Ainda que tardio, uma vez que se refere ao último terço do século XVII, o seu diário é um raro registro de aspectos da luz aplicada naqueles teatros, devido à raridade das informações sobre o assunto.

A mais recente publicação dos mencionados diários foi editada por Merit Lane e Börge Magnusson, em 2002, sob a responsabilidade do National Museum de Estocolmo; Trata-se de um livro raro que deveria estar à disposição em instituições que, interessadas efetivamente na práxis cênica, incluam a compreensão da sua natureza visual como objeto da pesquisa teatral qualificada. As observações sobre os diários de Tessin, aqui apresentadas, baseiam-se nos comentários e citações do estudioso Gösta Mauritz Bergman (1977). É possível identificar nos relatos de Tessin a aplicação de padrões já demonstrados por Sabbattini e Furttenbach. Ele indica, contudo, novos elementos incorporados à contribuição da luz para cena.

Além dessas anotações, Tessin deixou 31 desenhos, que se referem às óperas Germanico sul Reno e Adone, espetáculos que ele assistiu em 1676, no Teatro di San Luca ou di San Salvador. Seu texto inclui observações acerca do maior teatro de Veneza no período, o San Giovanni Grisostomo. ${ }^{21}$ que inaugurado em 1678, apre-

\footnotetext{
20 Nicodemus Tessin, o jovem - homônimo do seu pai, Nicodemus Tessin, o velho (1615-1681) - era um arquiteto sueco que estudou em Roma e Paris, na segunda metade do século XVII. Nesse período ele visitou Veneza e registrou observações em diários de viagens. Tessin, o filho, ocupou o lugar de seu pai, como arquiteto da cidade de Estocolmo. O principal projeto a ele atribuído é a reconstrução do Palácio Real da capital sueca, destruído pelo fogo em 1697.

21 O espaço destinado à cena media 32,5 metros de profundidade, incluindo um proscênio, cuja extensão, desde a ribalta até a cortina, tinha 4,2 metros, configurando o até hoje reconhecido "palco italiano", com um proscênio projetado entre a plateia e a caixa cênica.
} 
sentava importante tratamento, não somente da cenotécnica, mas também dos instrumentos, suportes e acessórios aplicados à luz para a cena.

Os comentários de Bergman (1977) dão conta de três principais aspectos nos sistemas encontrados por Tessin:

I. varas verticais cilíndricas de madeira, afixadas no fosso, que apresentavam suportes para luzes em diferentes distâncias do piso do palco e podiam girar no próprio eixo, permitindo que o palco fosse iluminado ou escurecido; esses suportes eram constituídos de elementos com três lados, provavelmente aplicando algum processo de reflexão, permitindo emissão da luz na direção desejada e bloqueio na face que se desejava escurecer;

2. uma espécie de vara horizontal, disposta atrás de elementos cenográficos aéreos, na qual podiam ser instaladas espécies de arandelas cujo mecanismo permitia que elas fossem giradas para também prover controle para a luz emitida emdireção ao palco. Nota-se que as luzes dispostas acima do palco eram limitadas, o que Tessin sublinha como medida de segurança contra o alto risco de incêndio, uma vez que, devido aos mencionados elementos aéreos da cenografia, a região acima do palco já era substancialmente ocupada, exigindo muito cuidado;

3. outro importante dado a ser levado em consideração é a aplicação da transparência para efeitos como o sol, a lua, estrelas e janelas, com um papel sobre o qual se aplicava algum tipo de óleo. Tais efeitos incluíam o uso do vidro, cujo brilho fascinava o espectador da época.

Um depoimento do próprio Nicodemus Tessin, a respeito de uma mudança de ambiente e atmosfera, que ele testemunhou no Teatro di San Giovanni Grisostomo, demonstra o papel da luz na práxis teatral do Barroco: "[...] como uma sala completamente iluminada e sedutora se converteu numa medonha caverna, o que foi completamente maravilhoso devido à extrema diferença entre os dois cenários". ${ }^{22}$ (TESSIN apud BERGMAN, 1977, p. 97, tradução nossa) Vale sublinhar que tais movimentos no ambiente e na atmosfera eram realizados à vista do público, ou seja, com a cortina levantada.

Tal momento reafirma a compreensão que o artista envolvido com a cena desenvolveu, com um agudo sentido de interação entre a cena e a luz. Os movimentos executados dentro do espaço de um espetáculo, à vista do espectador,

22 "[...] how the quite illuminated enchanted room was converted into a terrible cave, which was quite wonderful because of the the extremes of the two such different sets." 
assim como a organização do libreto, incorporavam inúmeras possibilidades de interação com a luz artificial. No teatro do Barroco, portanto, a assertiva visual residia também no fascínio produzido pelas mudanças espetaculares que ocorriam diante do olhar do espectador.

\section{A CENA SOB OUTROS PONTOS DE VISTA}

Já em 1687, em Piacenza, quando Tessin começa a escrever seus diários sobre o teatro veneziano, apareceu uma mudança muito importante na abordagem visual do teatro. A gravura que representa a cenografia elaborada por Ferdinando (Bibiena) Galli (1657-1743), para a ópera Didio Giuliano (1687), de Bernardo Sabadini (ou Sabatini) na qual ele introduziu uma maneira inovadora de conceber a cena, através de uma mudança relativamente simples, o novo posicionamento do ponto de fuga (Figura 70). Agora deslocados do centro e localizados fora da imagem mostrada no palco, os novos pontos de fuga estabeleciam ângulos que revelavam a cena numa disposição dinâmica, por vezes assimétrica, conjugando-se ao princípio barroco de movimento. Tal tratamento da perspectiva seria denominado de "cena em ângulo" (scena per angolo), pelo próprio Ferdinando Bibiena, nos seus livros, A Arquitetura preparada com o uso da geometria e reduzida em perspectiva (L'Architettura civile preparata su la geometria e ridotta alle prospettive), publicado em 1711, e Orientações para os jovens (Direzioni ai Giovani), em 1731 (Figura 71). A história da ópera registra o apelo dessa inovação, resultando em grande atenção para os cenários. Os ensinamentos deixados por Brunelleschi, Alberti, Torelli e Pozzo, como exemplos, produziram frutos no trabalho da família Galli, inaugurando em Ferdinando uma trajetória que duraria aproximadamente um século, entre 1687 e 1780 .

A jornada inicia-se quando Giovanni Maria Galli [(1625-1665), pai de Ferdinando] demonstra talento e vontade de se tornar pintor, sendo enviado pelo seu pai - então governante da fortaleza toscana de Bibiena -, para estudar no atelier do pintor Francesco Albani (1578-1660), em Bologna. Ainda que sua família fosse de origem florentina, ao começar suas atividades com Albani e constatar que havia outro aprendiz com o nome idêntico ao seu, ele atendeu a um costume italiano e incorporou Bibiena como sobrenome, provavelmente respondendo à notoriedade que sua família lá alcançou. Outros estudiosos aceitam que ele tenha passado a ser conhecido assim, simplesmente por que Bibiena era o local do seu nascimento. 
Ao morrer, em 1664, Giovanni deixa o filho Ferdinando com sete anos de idade, que seria criado por um pupilo seu, Carlo Cignani (1628-1719), considerado depois o último grande pintor bolonhês. Ferdinando estudou arquitetura com a geração que sucedeu grandes construtores do Barroco. Além disso, trabalhou em colaboração com o famoso cenotécnico Ercole Rivani (?-1689), alcançando depois grande notoriedade na arquitetura teatral e na cenografia. Em 1708, em Barcelona, após supervisionar as festividades do casamento de Carlos III da Espanha ele se tornou o principal arquiteto e pintor, trabalhando sob os auspícios do rei. Quando Carlos III transferiu-se para Viena, em 1711, onde foi coroado Carlos VI rei da Boemia, convidou Ferdinando Bibiena que, aceitando, juntou-se ao irmão Francesco, já estabelecido na corte vienense. No ano 1702, Francesco Bibiena concebeu e supervisionou as festividades da recepção de Felipe V da Espanha, como rei das Duas Sicílias e de Maria Theresa de Hapsburg, como sua rainha. Chamado a Viena, pelo imperador germânico Leopold I, Francesco projetou o Teatro Nuovo, em 1704. Ele teria projetado ainda outros teatros, em Nancy, Roma e Verona que, infelizmente, desapareceram.

Ferdinando levou mais tarde para Viena seus filhos, Alessandro, de 24 anos de idade, e Giuseppe (1696-1756), nove anos mais jovem. Juntos criaram inúmeros dispositivos cenográficos provisórios para as celebrações da nobreza, durante toda uma geração, e essa associação gerou um enorme conjunto de aproximadamente duas centenas de desenhos, ainda que a maioria tenha sido perdida. Muitos dentre os projetos, desenhos e esboços - assinados por Ferdinando ou pelo seu filho Giuseppe - foram reproduzidos no período, em água forte e gravura. As atividades da família Bibiena geraram uma empresa que recebia encomendas para teatros em diversas cortes europeias, assim como cenários e decoração de festividades. Era um empreendimento multinacional; há documentos que registram a presença dos Bibiena em capitais como Berlim, Hamburgo, Paris, Madri, São Petersburgo e Viena, dentre outras (Figura 72).

O trabalho dos Bibiena pode ser comparado com o da empresa dos irmãos Brückner, Max e Gotthold, que trabalharam com a Companhia de Georg II, o Duque de Sax-Meiningen, no século XIX, também fornecendo planejamento e execução de cenários por toda a Europa. A empresa dos Brückner trabalhou inclusive para Richard Wagner (1813-1883), no Teatro Bayreuth, projetando e executando os cenários que Adolphe Appia consideraria esteticamente obsoletos. Os cenários dos Brückner são periodicamente expostos e revelam a qualidade, sem precedentes, do estilo romântico de bases realistas. 
Na maneira de tratar visualmente a cena, introduzida por Ferdinando Bibiena, é importante sublinhar o citado deslocamento dos pontos de fuga do centro da imagem e as consequentes diagonais, acentuando a obliquidade do ambiente, o que incorporou virtual expansão ao espaço da cena, que se projetava para "fora do palco". O ambiente da ação parecia romper as fronteiras da boca de cena e dos bastidores, provocando o espectador a imaginar uma dimensão dilatada. A busca de uma síntese eloquente que buscava mixar o espaço da natureza com a materialidade geométrica do espaço construído pelo homem (as construções arquitetônicas), radicalizava-se através de uma intervenção na ordem inicial renascentista que impunha uma espécie de centralidade imutável associada à simetria promovida pelo ponto de fuga único.

Pode-se, até certo ponto, considerar uma espécie de antiepifania perspectivista: o espaço da cena já não se oferece integralmente ao espectador, que apreende sua provável extensão através de um fragmento irregular, assimétrico, implantado na cena. Por outro lado, esse grau de desconhecimento do todo é, por assim dizer, relativizado: assimilando o padrão arquitetônico em questão ele pode operar associações, interpretando a composição e construindo em imagens mentais uma sucessiva busca da totalidade. Os vários pontos de fuga introduzidos pela scena per angolo através de perspectivas múltiplas elaboravam uma disposição que parecia "sugar" o espectador, colocando-o no interior de um espaço cênico com nova dinâmica uma vez que seus limites eram projetados para fora dos limites do palco.

É possível apreender um discurso visual em operação; a proposição de Brunelleschi ainda sobrevivia, pois, na contemplação do espaço de Deus agora geometrizado numa entidade pensada e quantificada pelo artista-cientista-filósofo, o observador aceitava instalar-se numa relação matemática que o dispunha em um lugar ideal precisamente calculado, integrando ponto de fuga e linha do horizonte para efetivar a representação bidimensional da realidade (tridimensional). Trata-se de uma equação visual impregnada pelo pensamento filosófico em ebulição. Na proposição da scena per angolo, ao implodir limites físicos do edifício teatral sobrepujando a moldura da boca de cena, o espaço artificializado abraça o ser humano representado pelo observador e o integra em um todo inacabado, "infinito".

Pouco se pode dizer da práxis cênica propriamente dita, no que se refere à aplicação objetiva dos desenhos dos Bibiena no espetáculo do Barroco e, consequentemente das relações com a luz. É possível, contudo, inferir que os procedimentos disseminados pela Itália, e descritos por Tessin, tenham sido aplicados pela família Bibiena. A incorporação da luz aos eventos podia parecer um movimento 
esperado, a ponto de ser dispensável sua abordagem teórica, mesmo no campo da descrição. Havia o flagrante interesse pela crescente parceria entre a arquitetura, inclusive como componente do real construído pelo ser humano, e o teatro que, por sua vez, se interessava em ampliar a compreensão da vida questionando sua representação limitada pelo interior de um espaço arquitetônico fechado que a enclausurava.

Um cenógrafo-arquiteto-pintor do Barroco poderia ser capaz de projetar um espaço cênico capaz de se estender e abraçar o espectador, integrando-o ao ambiente e, portanto, até destruindo os limites da realidade objetivamente construída pelo ser humano. A incapacidade da luz de convencer o espectador de que o revelado no palco representa a realidade, ou é uma extensão da realidade objetiva que ele constrói no cotidiano, instala, contudo, certas crises nessa relação.

Em correspondência efetivada durante os anos 1738-1739, o francês Charles de Brosses, ${ }^{23}$ (1709-1777) compara os teatros da Itália com aqueles que via no seu país, considerando a eficácia italiana. Tal julgamento parece conter certo exagero, tanto quanto o daqueles que rotulam a scena per angolo apenas como um desejo de virtuosismo dos arquitetos e tentativa de incorporar certa variação nos seus projetos, uma vez que se tratava de estéticas com origens e objetivos diferenciados. Aliás, pareceria equívoco qualificar negativamente a proposta de variar a abordagem visual num projeto para a cena. Charles de Brosses dá testemunho da resposta que essa espécie de cenografia provocava no público:

É realmente uma sacada, uma floresta, um lugar no campo, uma choupana, um calabouço etc. Ao invés de dispor os elementos cenográficos de modo uniforme em duas ranhuras na coxia, como fazemos [na França], eles os distribuem por todo o palco, sejam pilares ou sacadas, eles os colocam de modo oblíquo, em várias diagonais, o que amplia o efeito de perspectiva. [...]: se deve ser um pequeno ambiente eles reduzem o palco e bloqueiam tão bem todas as laterais que se pode dizer que estamos numa caverna, numa tenda, ou sob uma abóboda. ${ }^{24}$ (DE BROSSES apud BERGMAN, 1977, p. 113, tradução nossa)

\footnotetext{
23 Charles-Nicolas Cochin, o Jovem, conde de Tournai e de Montfalcon, autor, cuja obra mais reconhecida é Cartas familiares sobre a Itália (Lettres familières sur l'Italie), publicada postumamente em 1799, depois de larga circulação em manuscrito.

24 "It is really a gallery, a forest, a camp, a shed, a room, a dungeon, etc. Instead of placing uniformally, as we do, the décor-elements in the two wing alleys, they distribute them all over the stage, whether they are colonnades or galleries, they place them obliquely on several diagonal lines, which increase the effect of perspective [...] if there should be a small room, they limit the stage and close it so well from all sides that one may say that one is in a cavern, in a tent or under a vault."
} 
O interessado na visualidade da práxis cênica deve usar de cautela na observação de depoimentos dessa natureza. O espectador, e até mesmo o artista envolvido com a cena tende a reagir efusivamente aos "efeitos,", a tudo o que especialmente surpreende sua visão, como algo que o projeta para fora de experiências cotidianas, no sentido de impulsionar a fantasia. O iluminador da atualidade pode evitar render-se ao senso comum ou pode transformar seus projetos em sucessões de efeitos que reduziriam a proposição estética de um espetáculo à superficialidade que até mesmo certos artistas parecem desejar quando clamam pelo movimento sem justificativa, pela cor sem propósito, e assim por diante.

No depoimento de Charles de Brosses, a perspectiva é destacada como responsável por estabelecer uma visão daquilo que pretende o cenógrafo, um efeito capaz de convencer o espectador de que ele está diante de um fragmento do seu próprio cotidiano. O seu relato deixou, contudo, um dado muito importante para a apreensão da estética buscada na scena per angolo. Quando dizia que os elementos cenográficos eram distribuídos em sentido oblíquo no palco ele poderia estar questionando a proposição cenográfica que considerava apenas a disposição de telões paralelos à boca de cena, nos quais a obliquidade era exclusivamente pintada.

Deve-se considerar a dificuldade em definir soluções técnicas que não apresentem desvantagens. No caso específico do modo elaborado pelos Bibiena, de acordo com depoimentos da época, a mudança de cenários durante os espetáculos era operada com visível dificuldade, gerando certa confusão no palco. Bergman (1977) menciona os comentários, no diário do arquiteto sueco Erik Palmstedt, referindo-se a observações sobre o teatro, em viagens à Itália:

Não há nenhuma máquina em nenhum desses teatros, de modo que as tapadeiras são movidas manualmente, uma a uma, e a mudança é executada enquanto a cena acontece. Não é agradável ver os maquinistas carregando peças de cenários e velas no palco, enquanto os atores estão representando. ${ }^{25}$ (PALMSTEDT apud BERGMAN, 1977, p. 116, tradução nossa)

Pode-se considerar aí um conflito entre a técnica cenográfica e a práxis barroca, na qual mudanças no dispositivo cenográfico eram processadas sob o olhar extasiado do espectador. Ainda que se possa desconfiar da total ausência de sistemas mecânicos para a mudança de cenários, naquele momento, na Itália, cabe considerar o testemunho de Palmstead, no que se refere à estranheza causada

25 "There are no machines at any of these theatres, so the wings are pulled out manually, one by one, and the change is going on all through that scene. It is not agreeable to see the stage hands carrying candles and pieces of decorations across the stage while the actors are engaged in reciting." 
por essas mudanças, que competiam com a performance, om os atores. Acentue-se o trânsito dos maquinistas, portando velas e cruzando o palco: aos olhos daqueles que se acostumaram às entradas e saídas de tapadeiras e elementos aéreos, como num passe de mágica - com a luz fora do alcance da visão - isso deveria gerar um enorme ruído. A necessidade de velas para iluminar o trajeto dos técnicos, revelando a mecânica das mudanças e sublinhando o palco, em detrimento do lugar da ação, podia gerar, como no caso em questão, reação negativa do público.

Bergman destacou as ilustrações do período para afirmar que a luz nelas representada não tem, necessariamente, relação com a luz da cena. Segundo ele, o brilho que se via ao nível do palco e a sua relação com as sombras pintadas, dificilmente corresponderia ao que era mostrado em cena, uma vez que, para isso, seria exigida uma disposição radicalmente assimétrica dos instrumentos de luz aplicados. Por outro lado, Bergman (1977) pondera que os teatros não contavam com um conjunto de superfícies refletoras capazes de produzir tal resultado. As casas de espetáculo do período, de acordo com a documentação disponível, contavam com sistemas conhecidos, ou seja: ribalta, luzes nas coxias, possíveis varas e alguns elementos móveis.

Os desenhos que sobreviveram não documentam particularmente a organização da luz. Em setembro de 1764, durante os trabalhos para a ópera Temístocles (Temistocle), em Stuttgart, o pintor de cenários Colomba revelou dificuldade para realizar seu trabalho, em carta destinada ao gerente Jacob Bühler: “[...] não fiz um desenho para a primeira cena por que preciso antes descobrir como as varas de luz podem ser alteradas de maneira que eu possa fazer um conjunto cenográfico inteiramente com peças irregulares". ${ }^{26}$ (COLOMBA apud BERGMAN, 1977, p. 116, tradução nossa)

Ainda que elementos cenográficos irregulares oferecessem muitas possibilidades, eles exigiam soluções inventivas e flexíveis: antes de definir um detalhe cenográfico, seria necessário planejar a atuação da luz já que, sem tal planejamento, o espaço da cena seria invisível. Isso vale para qualquer que seja a práxis cênica. Importante notar que as variáveis de um espetáculo que interagem com a luz são diversificadas. Por vezes, ao se tratar da cenografia, do figurino, da maquiagem, da dramaturgia, do ator, desconsidera-se ingenuamente a luz, como se fosse possível discutir a presença na cena de qualquer um dos seus aspectos (a imagem cênica) sem a contribuição da luz.

26 "[...] have not made a sketch for the first scene since I want to find out first whether light rods [varas] can be altered so that I can make an entirely irregular set of scenery." 
Seria proveitoso, portanto, ampliar os horizontes da crítica e trabalhar com a compreensão da cena como um conjunto de aspectos conectados transversalmente, o que inclui (ou tem como traço de união) a luz. Pode ser difícil para o neófito perceber que qualquer mudança em um dos mencionados aspectos com a intenção de propor caminhos diferenciados para a práxis cênica, interage organicamente com a luz. E até mesmo quando um teórico se refere a qualquer um dos elementos da cena - ou grupo de elementos - ele estará assumindo a presença da luz, a imagem. Mesmo que não se dê conta. 